Implementasi Pendayagunaan Zakat ... (Sudarno Shobron, Tafrihan Masruhan)

\title{
IMPLEMENTASI PENDAYAGUNAAN ZAKAT DALAM PENGEMBANGAN EKONOMI PRODUKTIF DI LAZISMU KABUPATEN DEMAK JAWA TENGAH TAHUN 2017
}

\author{
Sudarno Shobron, Tafrihan Masruhan, Muthoifin \\ Magister Pendidikan Islam, Universitas Muhammadiyah Surakarta \\ E-Mail: ss175@ums.ac.id
}

\begin{abstract}
Zakah is a treasure worship that is believed to be able to overcome social and economic problems. Not just to meet the basic needs of the mustahiq Zakat has the ability to develop people's economy. To get the maximum results zakat institutions need to do a lot of new studies and breakthroughs. Lazismu of Demak utilizes zakat for the development of productive economy with the goal of creating jobs, reducing unemployment and poverty. This is what makes researchers interested in conducting research to find out what kind of zakah implementation in the development of productive economy as well as the economic development mustahik after the implementation of zakat as a productive economy. Because it includes field research researchers used the Phenomenological approach data collected through observation, documents, questionnaires and interviews. Then, the data was analyzed sequentially and interactively consisting of three stages, namely: 1) data reduction, 2) data presentation, 3) conclusion drawing or verification. The productive use of zakat in developing productive economy consisted of traditional and creative uses. Traditional economic productive use was realized by providing working tool to mustahiq. Creative economic productive was conducted by providing capital in from of pure grant to mustahiq, provide a capital loan in a very easy way, not burdening the mustahiq and invest zakat funds into the real business sector. The zakat institution will receive capital invested and benefit from the businesses, then the capital and benefits will be used for ummah advantages. From the findings, it can be known that some participants of productive economy were able to develop their business well. Some others were only able to meet their basic daily needs. While some more others were less trustworthy in using capital loan provided.
\end{abstract}

Key words: Utilization of zakat; productive economy; in lazismu of Demak

Abstrak: Zakat adalah ibadah maliyah yang mampu mengatasi masalah-masalah sosial dan ekonomi. Selain memenuhi kebutuhan pokok para mustahiq, zakat mampu mengembangkan perekonomian ummat. Untuk mendapatkan hasil maksimal tersebut, lembaga-lembaga zakat perlu banyak melakukan kajian dan terobosan-terobosan baru. Seperti LAZISMU Demak yang mendayagunakan zakat untuk pengembangan ekonomi produktif dengan tujuan menciptakan lapangan pekerjaan, mengurangi pengangguran serta kemiskinan. Inilah yang mendorong diadakannya penelitian guna mengetahui seperti apa implementasi pendayagunaan zakat dalam pengembangan ekonomi produktif serta perkembangan ekonomi mustahiq setelah diimplementasikannya zakat sebagai ekonomi produktif. Karena termasuk penelitian lapangan (field research), peneliti menggunakan pendekatan Phenomenologis, data dikumpulkan melalui observasi, dokumen, angket dan wawancara, kemudian akan dianalisis secara berurutan dan interaksionis yang terdiri dari tiga tahap, yaitu: 1) Reduksi data, 2) Pernyajian data, 3) Penarikan simpulan atau verifikasi. Dari penelitian tersebut didapatkan hasil bahwa bentuk pengembangan ekonomi produktif di LAZISMU DEMAK meliputi tradisional dan kreatif. Ekonomi produktif tradisional meliputi pembelian alat kerja untuk mustahiq. Adapun ekonomi produktif kreatif melaui pemberian modal dalam bentuk hibah murni, memberikan pinjaman modal dengan cara yang sangat mudah, tidak membebani mustahiq dan menginvestasikan dana zakat ke sektor usaha nyata. Hasil investasi dimanfaatkan sebesar-besarnya untuk mustahiq. Dengan cara ini sebagian peserta ekonomi produktif mampu mengembangkan usahanya dengan baik, sebagian 
lagi hanya mampu memenuhi kebutuhan pokok sehari-hari dan sisanya kurang amanat dalam menggunakan pinjaman modal yang diberikan.

Kata Kunci: Pendayagunaan zakat; Ekonomi produktif; Lazismu Demak

\section{PENDAHULUAN}

Zakat adalah ibadah maliyah yang mempunyai nilai sosial dan spiritual. Penyebutan zakat di al Quran beiringan dengan shalat sebanyak delapan puluh dua ayat. ${ }^{1}$ Sehingga tidak heran jika Abu Bakar as Shiddiq khalifah Rasulullah sallallahu alaihi wa salam memerangi orang yang tidak mengeluarkan zakat. ${ }^{2}$ Imam Nawawi rahimahullah berkata, "Barangsiapa mengingkari kewajiban zakat di zaman ini, ia kafir berdasarkan kesepakatan para ulama. $^{3}$

Zakat juga diyakini mampu menjadi sumber keseimbangan perekonomian ummat, menciptakan lapangan pekerjaan dan mengurangi pengangguran serta kemiskinan. Namun, melalui lembagalembaga zakat yang ada ummat belum memaksimalkan potensi yang ada. Hal ini dikarenakan zakat hanya difahami sebagai pemberian kepada orang yang lemah atau memenuhi kebutuhan sesaat orang tersebut. ${ }^{4}$

LAZISMU Demak adalah salah satu lembaga zakat yang didirikan oleh Muhammadiyah Demak. Lembaga tersebut berkomitmen mengimplementasikan zakat sebagai solusi masalah perekonomian dan kemasyaraktan dengan memunculkan program Ekonomi Produktif. Hal ini lah yang mendorong diadakannya penelitian secara khusus di LAZISMU Demak.

Terkait dengan penelitian yang dilakukan, ditemukan beberapa hasil penelitian, jurnal dan tulisan yang bisa dijadikan pembanding dengan penelitian yang sedang dilakukan. Antara lain:

$1 \quad$ Sayyid Sabiq, Panduan Zakat Menurut Al Quran dan Sunnah ( Bogor: Pustaka Ibnu Katsir , 2005 ), hlm. 1

2 Abu Bakar Jaabir al-Jazairi, Minhajul Muslim ( Cairo : Daar el-Aqidah ,1999), hlm. 240

3 An Nawawi, Syarh Shohih Muslim, ( Damaskus : Dar. Marrifat : 1998 ) hlm. 205/1

4 Nabil Fathi al Mi'dawi, az. Zakat sabiil lil hilli al masyaakil al iqtisodiyah al ijtimaiyah ( Ciaro: Jami'atul al Azhar, 1998 ), hlm, 2
1. Muh Muhsin. H, (Program Pascasarjana Magister Hukum Islam Universitas Islam Negeri Alaudin Makasar, 2015) Implementasi Zakat Dalam Meningkatkan Perekonomian Umat Perspektif Hukum Islam (Studi Kasus di Badan Amil Zakat (BAZ) Kabupaten Barru. Penerimaan dana ZIS sangat terbatas karena ada anggapan bahwa ZIS milik pemerintah, anggapan ini muncul karena semua petugas ZIS adaah pegawai pemerintah. Sehingga perekonomian di Kabupaten Barru meningkat hanya di sektor tertentu.

2. Widyawati, (Sekolah Pascasarjana Uin Syarif Hidayatullah Jakarta, 2011) Filantropi Islam Dan Kebijakan Negara Pasca-Orde Baru:Studi tentang Undang-undang Zakat dan Undangundang Wakaf. Hasil penelitian yang diperoleh menunjukkan bahwa, Islam memberikan perhatian yang sangat besar pada masalah kedermawanan, dari tingkat yang sekadar sukarela hingga ke tingkat yang bersifat wajib, dengan shadaqah sebagai konsep utamanya..

3. Damhuji, (Program Pascasarjana Fakultas Ilmu Budaya Universitas Gadjah Mada Yogyakarta, 2015) Elit Agama Islam dan Pengelolaan Zakat Di Kabupaten Bima NTB Dalam Perspektif Sejarah. Hasil penelitian ini: pada zaman kolonial Belanda dan Jepang pengelolaan zakat dihapus dan mengakibatkan lahirnya tradisi pembayaran zakat secara personal di Bima. Pengelolaan zakat periode 19681979 sebagai periode sukses; periode 1980-1999 sebagai periode yang kelam; dan periode 2000-2005 sebagai periode kebangkitan kembali.

4. Rahman, Habibur ( Institut Agama Islam Negeri Sunan Ampel Surabaya Jurusan Muamalah, 2009) Tinjauan Hukum Islam Terhadap Implementasi Penyaluran Zakat Untuk Beasiswa Pendidikan Oleh Laznas Baitul Maal 
Hidayatullah (BMH) Surabaya. Hasil dari penelitian ini antara lain; ketidak puasan masyarakat terhadap kinerja pemerintahan memicu masyarakat untuk mencari sumber dana alternatif lainnya yaitu zakat yang diharapkan mampu mengentaskan permasalahan kemiskinan dan pendidikan. Penelitian ini tidak berbicara terkait zakat sebagai ekonomi produktif.

5. Hafidhuddin, Didin; dalam bukunya "Zakat dalam Perekonomian Modern", menjelaskan bahwa zakat bisa menjadi salah satu solusi pemerataan ekonomi dan pemberdayaan mustad'afin, dengan menyalurkannya pada usaha-usaha produktif. $^{5}$

6. Thoriquddin, Mohammad; dalam bukunya " Pengelolaan Zakat Produktif (Perspektif Maqasid al Syariah Ibnu Asyur)" menjelaskan bahwa pengelolaan zakat produktif merupakan fenomena baru dalam pengumpulan dan pendistribusian zakat, zakat dikelola agar mengahasilkan sesuatu secara terus menerus. Buku ini adalah salah satu bentuk penelitian yang bertujuan mengetahui bagaimana pengelolaan zakat produktif di el-zawa UIN Maliki Malang. ${ }^{6}$

7. Beik, Irfan Syauqi; (Zakat \& Empowering Jurnal Pemikiran dan Gagasan, -Vol II 2009) Analisis Peran Zakat dalam Mengurangi Kemiskinan : Studi Kasus Dompet Dhuafa Republika. Hasil penelitian ini menunjukkan Hasil analisa menunjukkan bahwa zakat mampu mengurangi jumlah keluarga miskin dari84 persen menjadi 74 persen. Kemudian dari aspek kedalaman kemiskinan, zakat juga terbukti mampu mengurangi kesenjangan kemiskinan dan kesenjangan pendapatan,

8. Pratama, Yoghi Citra (The Journal of Tauhidinomics Vol. 1 No. 1 (2015): 93104 ). Peran zakat dalam penanggulangan kemiskinan ( Studi Kasus : Program

5 Didin Hafifuddin, Zakat Dalam Perekonomian Modern (Jakarta: Gema Insani Press, 2002)

6 Mohammad Thoriquddin, , Pengelolaan Zakat Produktif ( Perspektif Maqasid al Syariah Ibnu Asyur ( Malang : UIN-Maliki Press, 2015)
Zakat Produktif Pada Badan Amil Zakat Nasional) UIN Syarif Hidayatullah Jakarta

9. Hasil penelitian ini didapatkan bahwa karakteristik mustahik yang memperoleh dana zakat produktif dari Baznas didominasi dari gender perempuan, dimana berdasarkan penelitian ini kaum perempuan mencapai 92,5\%. Secara keseluruhan mustahik menilai program zakat produktif sudah berjalan dengan sangat baik. Dari data empirik diatas dapat disimpulkan bahwa meskipun dana zakat yang terkumpul masih sangat kecil, tetapi memiliki dampak nyata dalam upaya pengentasan kemisikinan melalui program zakat produktif. Dan zakat menjadi instrument keuangan yang efektif dalam permasalahan modal kaum miskin.

10. Syaiful; Suwarno, (BENEFIT Jurnal Managemen dan Bisnis ; Volume 19, Nomor 2, Desember 2015: 150-160 ), Kajian pendayagunaan zakat produktif sebagai alat pemberdayaan ekonomi masyarakat (mustahiq) pada LAZISMU pdm di kabupaten gresik. Hasil Penelitian ini adalah: Tidak banyak masyarakat tahu bagaimana cara pemberdayaan zakat untuk mustahik. Bahkan sebagaian dari mereka mengatakan tidak boleh. Adapun Pemanfaatan dana zakat sudah sesuai dengan sifat dan asal dari dana zakat tersebut.

11. Sartika, Mila (La_ Riba ; Jurnal Ekonomi Islam Vol. II, No. 1, Juli 2008). Pengaruh Pendayagunaan Zakat Produktif terhadap Pemberdayaan Mustahiq pada LAZ Yayasan Solo Peduli Surakarta. Berdasarkan hasil analisis data dengan bantuan program Windows SPSS 11.5 dari variabel jumlah dana (zakat) yang disalurkan dan variabel pendapatan mustahiq ditemukan besarnya pengaruh variabel jumlah dana(zakat) yang disalurkan terhadap pendapatan mustahiq sebesar $10,2 \%$. yang berarti sebesar 89, 8\% dari pendapatan mustahiq dipengaruhi oleh faktor lain.

12. Utami, Siti Halida; Lubis, Irsyad (Jurnal Ekonomi dan Keuangan Vol.2 No.6 tahun 2014) Pengaruh Pendayagunaan 


\section{Zakat Produktif Terhadap Pemberdayaan Mustahiq Di Kota Medan.}

Secara rata-rata, jumlah zakat produktif yang paling banyak disalurkan atau diterima oleh responden sebagai mustahiq adalah pada jumlah Rp 500.000Rp 1.000.000 dan tanggapan responden terhadap tingkat kecukupan jumlah zakat produktif yang diterima masih dalam jumlah yang kurang. Semua penelitian di atas, tidak ada kesamaan dengan penelitian yang dilakukan saat ini. Penelitian ini hendak menggambarkan bagaimana implementasi pendayagunaan zakat dalam pengembangan ekonomi produktif yang dilakukanolehLAZISMUKabupatenDemak Jawa Tengah Tahun 2017 serta bagaimana perkembangan dan perubahan ekonomi mustahiq di LAZISMU Demak setelah diimplementasikannya pendayagunaan zakat? Setelah diadakannya penelitian ini, diharapkan bisa diketahui sejauh mana penerapan pendayagunaan zakat dalam pengembangan ekonomi produktif yang dilakukan oleh LAZISMU Kabupaten Demak, begitu juga perkembangan atau perubahan ekonomi mustahiq LAZISMU Demak setelah diimplementasikannya pendayagunaan zakat.

\section{METODE PENELITIAN}

Metode penelitian yang digunakan adalah penelitian kualitatif. Penelitian kualitatif adalah penelitian riset yang bersifat deskripsi, cenderung menggunakan analisis dan lebih menonjolkan proses makna. ${ }^{7}$ Penelitian ini dilakukan pada Lembaga Amil Zakat Infaq dan Shadaqoh Muhammadiyah Kabupaten Demak yang beralamatkan di Jl. Kyai Jebat No. 09 Demak Jawa Tengah.

Jenis penelitian yang digunakan adalah penelitian lapangan (field research). Field Research adalah bentuk penelitian yang bertujuan mengungkapkan makna yang diberikan oleh anggota masyarakat pada perilakunya dan kenyataan sekitar. ${ }^{8}$ Dalam

\footnotetext{
7 Sugiyono, Metode Penelitian Kualitatif Komprehensif ( Bandung: AlfaBeta, 2015),hlm.14. ; Nanang Budi Utomo, Metode Penelitian kualitatif, 2016. ( http : // bukubiruku.com, diakses 27 Oktober 2017).

8 Salmon priaji martana, problematika penerapan
}

penelitiannya digunakan pendekatan Sosiologis, yaitu menggambarkan kondisi masyarakat secara lengkap dengan struktur, lapisan dan berbagai gejala sosial yang saling berkaitan. ${ }^{9}$ Penelitian ini juga akan dilengkapi dengan pendekatan Phenomenologis. Yaitu, pendekatan yang dilakukan secara mendalam terhadap suatu fenomena yang menyita perhatian masyarakat luas karena keunikan dan kedahsyatan fakta tersebut. ${ }^{10}$.

Populasi dalam penelitian ini adalah mustahiq yang tergabung dalam anggota ekonomi produktif sebanyak 44 orang, namun yang dilakukan penelitian secara langsung kepada mereka sejumlah 35 orang. Sisanya didapatkan data global mereka dari informan penelitian, yaitu Kepala LAZISMU Demak dan tenaga eksekutifnya. Pengumpulan data pada penelitian ini, teknik yang digunakan adalah observasi, dokumen, angket dan wawancara, seperti layaknya penelitian lapangan. ${ }^{11}$

Untuk menganalisis data yang terkumpul, digunakan analisis data diskriptif kualitatif. Yaitu, data yang terkumpul berupa kata kata tertulis atau lisan dari orang atau perilaku yang diamati melalui wawancara, observasi dan dokumentasi yang diproses melalui pencatatan dan lain-lain kemudian disusun dalam teks yang diperluas. ${ }^{12}$

Proses selanjutnya adalah menganalisis data secara berurutan dan interaksionis yang terdiri dari tiga tahap, yaitu: 1) Reduksi data, 2) Pernyajian data, 3) Penarikan simpulan atau verifikasi. ${ }^{13}$ Metode berfikir yang digunakan adalah metode berfikir deduktif. ${ }^{14}$

metode field research untuk penelitian arsitektur vernakular di indonesia, dimensi teknik arsitektur vol. 34, no. 1, juli 2006: 59 - 66

9 Tem Penyusun, Pedoman Penulisan Tesis.(Surakarta: Sekolah Pasca Sarjana Universitas Muhammadiyah Surakarta, 2016),hlm. 13.

$10 \quad$ Ibid. hlm 15

11 Ibid. hlm. 19.

12 Miles, MB, and A.M. Huberman.. Qualitative Data Analysis. ( Beverley Hills: Sage Pub. 1984),. hlm. 26.

13 Ibid. hlm. 16

14 Arikunto, Suharsimi.. Prosedur Penelitian Suatu Pendekatan Praktek ( Jakarta: Rineka Cipta,1992), hlm. 159. 


\section{HASIL DAN PEMBAHASAN}

Zakat dimaknai secara luas dengan memberikan sebagian dari harta kepada orang-orang yang telah ditentukan oleh Allah SWT yaitu orang muslim yang fakir dan golongan tertentu lainnya. ${ }^{15}$ Hukum zakat adalah wajib. Wajibnya zakat telah dijelaskan dalam al Quran maupun Hadits. Antara lain :

1) Al Quran. Q.S at Taubah ( 10$): 103$ .Artinya: "Ambillah zakat dari sebagian harta mereka, dengan zakat itu kamu membersihkan dan mensucikan mereka dan mendoalah untuk mereka. Sesungguhnya doa kamu itu (menjadi) ketenteraman jiwa bagi mereka. dan Allah Maha mendengar lagi Maha Mengetahui". ${ }^{16}$

2) Hadits

لاز لاق امهنع الل بضر رمع رنبا نع ملسلا

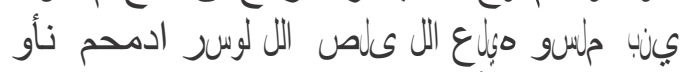

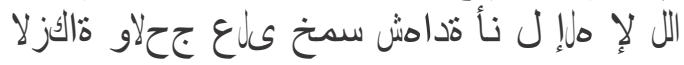

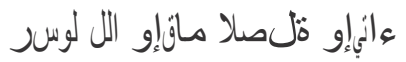

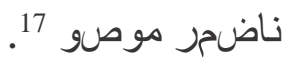

Artinya:" Dari Ibnu Umar berkata: Rasulullah shallallahu 'alaihi wasallam bersabda: Islam dibangun diatas lima (landasan); persaksian tidak ada ilah selain Allah dan sesungguhnya Muhammad utusan Allah, mendirikan shalat, menunaikan zakat, haji dan puasa Ramadlan" (HR. Muslim)

Orang yang mengingkari kewajiban zakat dihukumi murtad dari islam dan dibunuh karena kekufurannya. Orang yang enggan membayarnya -tapi meyakini kewajiban hukumnya- maka ia berdosa, tanpa dihukumi murtad dari islam. ${ }^{18}$ Zakat ada dua macam, yaitu: zakat maal dan zakat fitrah. Adapun Syarat Wajib Zakat

15 Sholeh Fauzan, Mulakhos Al Fiqhi.. ( Kairo; Darul Aqidah,2003), hlm. 249.

16 Departemen Agama RI, Al Quran dan Terjemahannya Edisi Doa,( Jakarta : PT.Cicero Indonesia ,2010 ), hlm. 203

17 Al Mundziri, Ringkasan Shohih Muslim : ( Jakarta : Pustaka Amani : 2003 ), hlm. 36

18 Sayyid Sabiq, Panduan Zakat Menurut Al Quran dan Sunnah ( Bogor: Pustaka Ibnu Katsir , 2005 ), hlm. 21 adalah muslim. Sedangkan harta yang wajib dizakati, juga mempunyai beberapa syarat antara lain: Cukup haul, Mencapai nishab, kepemilikan penuh, pemiliknya tidak dalam keadaan berhutang, hartanya berkembang

Macam-macam harta yang wajib dizakati, antara lain: Emas dan Perak serta Uang Tunai sejenisnya, perhiasan, tanaman, buah-buahan, hewan ternak dan harta karun. Setelah harta terkumpul, maka zakat dibagikan kepada delapan golongan yang berhak menerima zakat. Yaitu: Orang fakir dan orang miskin, amil/Pengurus zakat, muallaf, budak, orang yang berhutang, fie sabilillah dan ibnu sabil.

Zakat tidak harus dibagikan ke semua golongan yang ada, Yusuf Qardhawi menjelaskan bahwa, jika harta zakat yang terkumpul banyak hendaknya dibagikan merata ke semua golongan yang ada, dengan bagian yang sama atau berbeda sesuai dengan kebijaksanaan pemimpin. Akan tetapi, hendaknya fakir dan miskin selalu diutamakan. ${ }^{19}$

Tujuan utama disyariatkannya zakat bukanlah sekedar mengumpulkan harta, memenuhi kas lembaga zakat atau sekedar membantu orang-orang yang lemah. Tujuan yang paling tinggi adalah agar kemanusiaan itu di atas materi, agar manusia menjadi tuannya harta benda dan bukan budaknya. ${ }^{20}$ Melihat potensi dan tujuan zakat yang demikian hebat, pada tahun 2001 LAZISMU Demak didirikan. Berdirinya LAZISMU Demak diharapkan mampu mengelola zakat dengan manajemen yang baik, modern dan mampu membuktikan zakat bagian dari penyelesai masalah sosial masyarakat yang terus berkembang. Pendayagunaan Zakat di LAZISMU Demak, diwujudkan dalam beberapa hal. Antara lain: Konsumtif tradisional, yaitu dengan memberikan sesuatu yang langsung bisa dikonsumsi oleh mustahiq. Konsumtif kreatif, yaitu dengan membagikan zakat dalam bentuk pembagian alat-alat tulis kepada anak-anak sekolah, pakaian-pakaian pantas pakai kepada yang berhak menerimanya. Selain

\footnotetext{
19 Yusuf Qardhawi, Fiqih Zakat ( Beirut: Muassasah ar Risalah, 2000), hlm. 692.

20 Ibid, 858
} 
itu zakat juga didayagunakan dalam bentuk produktif tradisional dan produktif kreatif.

\section{Penerapan Pengembangan Ekonomi Produktif di LAZISMU Demak}

Pendayagunaan Zakat untuk Ekonomi Produktif yang dikembangkan di LAZISMU Demak, ada empat macam: ${ }^{21}$

a. Pengembangan Ekonomi Produktif tradisional; Pendayagunaan zakat produktif yang bersifat tradisional adalah dengan membantu mustahiq sehingga mustahiq bisa bekerja atau mendapatkan lapangan pekerjaan, hal ini diwujudkan dengan membelikan peralatan kerja. Hal ini sudah cukup tepat. Disebutkan oleh Yusuf Qardhawi, "Apabila seseorang berprofesi sebagai ahli pertanian, maka ia diberikan zakatnya berupa dana awal yang dapat digunakan membeli alat-alat pertanian secara permanen. ${ }^{22}$

b. Pemberian modal/Hibah; Hal ini dilakukan dengan cara memberikan hibah modal kepada muzakki yang betul-betul membutuhkan. Program hibah murni modal, ini kurang berhasil disebabkan; LAZISMU Demak belum mempersiapkan diri dengan baik, hal ini dibuktikan dengan belum adanya team lapangan yang profesional dan mustahiq yang dipilih oleh LAZISMU Demak belum bisa bersikap profesioal dan jujur. Sehingga tidak memanfaatkan dana yang diberikan sesuai peruntukannya.

c. Peminjaman modal/Dana Bergulir kepada anggota yang perekrutan atau pemilihan anggota nya dilakukan oleh Ibu-ibu Aisiyah yang tergabung dalam Pimpinan Daerah dan Pimpinan Cabang Aisyiyah, jumlah anggota ekonomi produktif mencapai empatpuluh empat orang. Dengan kriteria: Muslim/muslimah yang taat beragama, tergolong kurang mampu, masih mampu untuk bekerja/punya usaha dan siap mengikuti ketentuan-

21 Wawancara dengan pengurus lazismu Demak dan petugas hariannya, pada hari Sabtu, 7 Oktober 2017

22 Yusuf Qardhawi, Spektrum Zakatdalam Membangun Ekonomi Kerakyatan(Jakarta: Zikrul Media Intlektual Terjemahan Sari Natulita, Lc, 2005), hlm , 10 ketentuan yang diberlakukan di program Ekonomi Produktif. Pemberian dana bergulir/qardhul hasan dilakukann dengan cara mustahiq mengangsur modal yang dipinjam setelah usahanya membuahkan hasil. Menukil dari Khalid Abd. Razaq dalam bukunya yang berjudul 'An Masarif Zakat wa Tamlikuha, Moh. Thoriquddin mengatakan: " Para ulama klasik belum ada yang membahas masalah ini (kredit harta zakat. peneliti), namun ulama kontemporer membolehkan mengkreditkan harta zakat. Di antara ulama ini adalah: Muhammad Abu Zahrah, Husain Makhluf, Hasan Abd. Rahman, dan Yusuf Al Qardhawi. Mereka beralasan bahwa hutang yang kembali tersebut berasal dari harta zakat, maka alangkah lebih baik jika harta zakat dikreditkan (dipinjamkan) dengan cara bebas riba agar kembali lagi ke Baitul Mal, sehingga orangorang Islam tidak terjebak dalam praktek riba. ${ }^{23}$ Pendapat ini sejalan dengan pendapat jumhur ulama yang mengatakanbahwa huruf lam dalam surat at Taubah(9); 60 tersebut bukan bermakna li al tamlik akan tetapi $l i$ ajl maksudnya adalah li ajli al-masraf (untuk penyaluran). ${ }^{24}$ Jika melihat dari berbagai data dan sudut pandang yang ada dalam persoalan meminjamkan harta zakat ini, apa yang dilakukan oleh LAZISMU Demak sudah tepat. Akan tetapi belum tentu tepat dilaksanakan di daerah lain. Hal ini disebabkan: LAZISMU Demak telah berusaha membagikan zakat sekaligus memberikan hak milik kepada mustahiq dalam bentuk bingkisan sembako, THR (santunan) menjelanghari raya untuk memenuhi kebutuhan konsumtif mustahiq, LAZISMU Demak telah melakukan uji coba memberikan dana hibah murni untuk modal, akan tetapi gagal karena mustahiq kurang amanah, kondisi sosiologis masyarakat yang cenderung

23 Moh.Thoriquddin, Pengelolaan Zakat ProduktifPerspektif Maqashid as SyarihIbnu 'Asyur, (Malang: UIN-Maliki Press: 2015), hlm. 43-44

24 Ibid; hlm. 142-143 
konsumtif, LAZISMU Demak tidak mengenakan beaya apapun kepada mustahiq/peminjam meskipun sekedar beaya administrasi, sebagian besar anggota program ekonomi produktif dan masyarakat sekitarnya tidak didapatkan dalam keadaan kelaparan atau membutuhkan penanganan darurat. Memberikan pinjaman modal untuk usaha produktif sebagaimana yang dilakukan oleh LAZISMU Demak tidaklah bisa dikatakan sebagai bentuk menahan harta zakat sebagaimana alasan fihak yang kurang setuju zakat dibagikan dalam bentuk pinjaman yang harus dikembalikan lagi. Karena di antara tujuan zakat adalah untuk memberi kecukupan pada mereka, dengan berbagai cara yang baik dan kondisional.

d. Menginvestasikan dana zakat yang terkumpul; sistemnya menempatkan uang zakat di usaha-usaha nyata dan hasilnya kembali kepada kas LAZISMU Demak. Ini dilakukan agar dana yang terkumpul bisa berkembang dan bisa dipergunakan untuk menambah anggaran pos-pos yang telah ditentukan atau menambah peserta ekonomi produktif maupun konsumtif. Menginvestasikan dana zakat pada sektor usaha real adalah termasuk jenis pengembangan usaha produktif kreatif yang dipraktekkan oleh LAZISMU Demak. permasalahan ini telah lama menjadi kajian para ulama, serta dicarikan payung hukum atau solusinya. Banyak hal yang terkait dengan permasalahan investasi zakat di dunia industri. Menginvestasikan dana zakat di proyek-proyek ekonomi atau usaha yang menghasilkan sebagaimana yang dilakukan LAZISMU Demak, sudah cukup tepat, dengan syarat beberapa kebutuhan pokok mustahiq sudah terpenuhi (sesuai dengan daerah dan kondisi seseorang). Tujuan menginvestasikan dana zakat di usaha-usaha yang profit adalah untuk mendapatkan manfaat dan hasil lebih besar yang kemudian digunakan untuk kemaslahatan fakir dan miskin lagi. Undang-Undang Republik
Indonesia Nomor 23 Tahun 2011 Tentang Pengelolaan Zakatsemakin memperkuat lagi. Disebutkan dalam Bab III Pengumpulan, Pendistribusian, Pendayagunaan, Dan Pelaporan Bagian KetigaPendayagunaanPasal27(1)Zakat dapat didayagunakan untuk usaha produktif dalam rangka penanganan fakir miskin dan peningkatan kualitas umat. (2) Pendayagunaan zakat untuk usaha produktif sebagaimana dimaksud pada ayat (1) dilakukan apabila kebutuhan dasar mustahik telah terpenuhi. (3) Ketentuan lebih lanjut mengenai pendayagunaan zakat untuk usaha produktif sebagaimana dimaksud pada ayat (1) diatur dengan Peraturan Menteri. ${ }^{25}$

Disebutkan dalam fatwa MUI, dana zakat yang diberikan kepada fakir miskin dapat bersifat produktif. Di bagian fatwa lainnya, salah satu bentuk zakat produktif itu ialah yang diinvestasikan. Hukum menginvestasikan dana zakat diperbolehkan dengan beberapa catatan. Syaratnya, investasi dana zakat disalurkan pada usaha yang dihalalkan syariat dan peraturan yang berlaku, usaha itu di yakini memberi keuntungan berdasarkan studi kelaikan, pembinaan dan pengawasan oleh pihak berkompeten termasuk lembaga yang mengelola dana investasi itu. Juga tidak terdapat fakir miskin yang kelaparan dan memerlukan biaya serta tak bisa ditunda saat zakat diinvestasikan. ${ }^{26}$

\section{Perkembangan Ekonomi Mustahiq}

Secara umum, keadaan ekonomi mustahiq peserta ekonomi produktif belum mengalami peningkatan yang signifikan, misalnya sampai menjadi muzakki. Namun demikian, sepuluh orang dari tiga puluh lima orang yang diteliti secara jelas mengatakan usaha dan pendapatannya meningkat. Secara umum mereka mampu

\footnotetext{
25 Mona, Himpunan Peraturan PerundangundanganRepublik Indonesia; Undang-undang Pengelolaan Zakat (Yogyakarta: Pustaka Mahardika,), hlm. 14.

26 Mukhtar Sadili, amru (ed).2003.Problematika Zakat Kontemporer: Artikulasi Proses Sosial Politik Bangsa. Jakarta: Forum Zakat. hal. 45
} 
memenuhi kebutuhan pokoknya seharihari, lebih leluasa dan mudah memutar modal yang ada. Kegiatan ekonomi yang dijalankannya semakin baik dan menghasilkan, sehingga pemasukan hasil penjualan/omset menjadi bertambah. Akan tetapi ada juga yang tidak mengalami kenaikan atau tidak berkembang, bahkan ada yang gagal dalam usahanya, sehingga tidak bisa mengembalikan modal yang dipinjamkan.

Pengembangan ekonomi produktif yang dilakukan LAZISMU Demak mulai dari hibah modal usaha, pemberian dana bergulir/qardhul hasan dan penginvestasian di usaha nyata/real tujuannya adalah untuk menggiatkan kegiatan ekonomi dan mengurangi pengangguran. Menurut Qardhawi, pengangguran adalah salah satu sumber permasalahan yang berkaitan dengan kegiatan perekonomian, hubungan kemasyarakatan dan juga permasalahan kemanusiaan. Apabila masalah pengangguran ini tidak dapat diselesaikan, maka akan muncul bahaya yang semakin hari semakin meluas dan berdampak buruk bagi kehidupan individu masyarakat, keluarga dan juga masyarakat secara umum. ${ }^{27}$

\section{KESIMPULAN}

Pendayagunaan zakat dalam bentuk pengembangan ekonomi produktif adalah sesuatu yang perlu dan penting. Di antara tujuannya, agar manfaat zakat tidak habis dalam waktu sesaat. Namun, bisa memiliki waktu lebih lama dan menghasilkan manfaat yang lebih besar dan luas. Pembahasan-pembahasan yang tersebut di atas dapat disimpulkan: 1). Pendayagunaan zakat yang dilakukan oleh LAZISMU Demak dalam pengembangan ekonomi produktif melalui berbagai cara. Antara lain: Produktif Tradisional dan Produktif Kreatif. 2). Pendayagunaan zakat dengan mengembangkan ekonomi produktif oleh LAZISMU Demak, mempunyai beberapa dampak positif. Antara lain: a). Peserta program ekonomi produktif benar-benar merasa terbantu dengan adanya pinjaman modal, b). Peserta program ekonomi produktif sangat senang dengan sistem yang diterapkan oleh LAZISMU Demak Yaitu; tidak ada uang administrasi, tidak ada denda keterlambatan, mulai mengangsur setelah usahanya membuahkan hasil, c). Meskipun ada beberapa orang yang menyalahgunakan dana dengan tidak menggunakan seluruh dana untuk pengembangan usaha, akan tetapi hal ini dikarenakan belum ada pengawasan secara ketat oleh LAZISMU Demak, d). Dari 44 peserta program ekonomi produktif, sepuluh orang secara jelas mengatakan omset dan usahanya meningkat dan mulai bisa. Sisanya mengatakan, bahwa usahanya mengalami peningkatan dari segi pemasukan dan hasil usahanya mampu untuk memenuhi kebutuhan sehari-hari, e). Peserta program ekonomi produktif merasa senang karena mampu mengembangkan usahanya dan bisa bergerak lebih leluasa setelah mendapatkan bantuan pinjaman modal.

27 Ibid,hlm. 4

\section{DAFTAR PUSTAKA}

al-Jazairi, Abu Bakar Jaabir. 1999.Minhajul Muslim . Cairo : Daar el-Aqidah

Amru, Mukhtar Sadili,. 2003. Problematika Zakat Kontemporer: Artikulasi Proses Sosial Politik Bangsa. Jakarta: Forum Zakat.

Al Mundziri.2003. Ringkasan Shohih Muslim . Jakarta : Pustaka Amani

al Mi'dawi, Nabil Fathi. 1998. az Zakat sabiil lil hilli al masyaakil al iqtisodiyah al ijtimaiyah . Ciaro: Jami'atul al Azhar

An Nawawi, Syarh Shohih Muslim.1998. Damaskus : Dar.Ma'rifat

Departemen Agama RI. 2010. Al Quran dan Terjemahannya Edisi Doa,( Jakarta : PT.Cicero 
Indonesia.

Fauzan, Sholeh Mulakhos Al Fiqhi. 2003. Kairo: Darul Aqidah.

Hafifuddin, Didin.2002. Zakat Dalam Perekonomian Modern .Jakarta: Gema Insani Press

Martana, salmon priaji, problematika penerapan metode field research untuk penelitian arsitektur vernakular di indonesia, dimensi teknik arsitektur vol. 34, no. 1, juli 2006: 59 - 66

Miles, MB, and A.M. Huberman.. Qualitative Data Analysis. ( Beverley Hills: Sage Pub. 1984

Mona, Himpunan Peraturan Perundang-undanganRepublik Indonesia;

Muthoifin, Nuha, Kontekstualisasi Makna Zakat: Studi Kritis Konsep Sabilillah Menurut Masdar Farid Mas'udi. (www.Publikasiilmiah.ums.ac.id, diakses 24 Desember 2017)

Undang-undang Pengelolaan Zakat.Yogyakarta: Pustaka Mahardika..

Sabiq, Sayyid. 2005. Panduan Zakat Menurut Al Quran dan Sunnah. Bogor: Pustaka Ibnu Katsir .

Qardhawi, Yusuf. 2000. Fiqih Zakat. Beirut: Muassasah ar Risalah 2005. Spektrum Zakatdalam Membangun Ekonomi Kerakyatan. Jakarta: Zikrul Media Intlektual Terjemahan Sari Natulita, Lc

Sugiyono, 2015.Metode Penelitian Kualitatif Komprehensif (Bandung: AlfaBeta

Suharsimi, Arikunto.1992. Prosedur Penelitian Suatu Pendekatan Praktek . Jakarta: Rineka Cipta.

Tem Penyusun. 2016. Pedoman Penulisan Tesis. (Surakarta : Sekolah Pasca Sarjana Universitas Muhammadiyah Surakarta,)

Thoriquddin, Mohammad.2015. Pengelolaan Zakat Produktif (Perspektif Maqasid al Syariah Ibnu Asyur. Malang : UIN-Maliki Press.

Utomo, Nanang Budi. 2016. Metode Penelitian kualitatif, ( http : // bukubiruku.com, diakses 27 Oktober 2017. 